\title{
MAKING SITES AND OBJECTS TALK: EXPERIENCES IN ACADEMIC RESEARCH, NEW TECHNOLOGIES AND COMMUNITY ENGAGEMENT
}

\author{
L. Medeiros ${ }^{1, *}$, J. Garcia-Fernandez ${ }^{2}$ \\ ${ }^{1}$ CHAM, Faculty of Human and Social Sciences, New University of Lisbon, Portugal - leonormedeiros@ fcsh.unl.pt \\ ${ }^{2}$ CIAUD, Faculty of Architecture, University of Lisbon, Portugal - jorgefernandez@ fa.ulisboa.pt
}

\author{
Commission II - WG II/8
}

KEY WORDS: Documentation, Remote Sensing, Surveying, Building Archaeology, Community Engagement, Collaborative Archaeology, Cultural Heritage.

\begin{abstract}
:
The identity and experience of past human societies has crystallized in the buildings that survive up to the present day, as architectural and archaeological heritage. The challenges of their study, management and communication are now in constant reshaping, as new technologies consistently bring new tools, opportunities and trials. Today, the values and meanings attached to this heritage by their communities are to be promoted by the strategies towards cultural heritage research, protection, enhancement, reuse or dissemination, as defined by the Faro Convention (CoE, 2005), but community involvement and interdisciplinarity are still goals often difficult to attain. In this contribution we aim to present two different case studies where strategies of state-of-the-art documentation and historicalarchaeological assessment were brought together to address communities' requests for heritage valorization while providing opportunities for interdisciplinary work, specialized education, and content creation. One is in the Finnish town of Hamina, a star-like fortress system which echoes the Renaissance urban ideals, achieved only in another place in Europe (Palma Nova, Italy), where an International Summer School took place to address the community's requests for study and documentation. Another is in the Portuguese village of Muge, Salvaterra de Magos, where the need for scientific study and documentation addressed the owner's goals for site musealization while providing interdisciplinary work and education to several undergrad and masters students in archaeology and architecture, while building contents for community engagement and outreach.
\end{abstract}

\section{INTRODUCTION}

\subsection{Community-based interdisciplinary work}

In this paper the focus goes to our built heritage and its associated integrated material heritage, including objects, machinery and other documents. As we go about our daily lives we are surrounded by man-made structures and objects that we take for granted but which are the result of millennia of technological evolution and accumulated knowledge. They are the reminders of the culture we are inserted in - both in time and space - and are silent witnesses of its reshaping and alteration. As we live in the palimpsests that are our cities and towns, the stories and knowledge these sites have to transmit are hard to decipher, often requiring an expert eye to be able to translate the symbols and marks into our current language. And sometimes the attention of the 'expert' is called in by the 'non-experts' to look at our recent past, to sites with little artistic value, of only local recognition, functional, and therefore not mainstream for conservation and enhancement needs, as is the case of the examples that follow.

The two projects presented in this paper, despite their importance in the creation of knowledge related to specific communities, uses and practices, history and technology, are here put under a different focus that brings up how community-based interdisciplinary work, with a focus on new technologies for documentation, is particularly suited to achieve the mission of academic work and the needs of local communities and of young generations of professionals. They depict the successful approach taken by the owners to establish links with academia to promote knowledge about the sites, communication and preservation, while strengthening ties between the different actors, and between people and place.

Furthermore, they also show the potential of new technologies to bring new perspectives on work with heritage, and how making education strategies combine both traditional and digital approaches to documentation and interpretation of heritage is a way to bring past and present communities together, creating new transboundary connections suited for a global world and highly digital youngsters.

In this paper we present two case studies, projects implemented in 2018 with a strong dimension of community involvement. We then explore how they connect to three relevant themes that were identified: the methodological approach used to give these sites a voice with which to share their stories, the need to reevaluate the role of the expert in heritage work when working with communities, and the diverse ways to integrate new technologies in order to achieve the scientific, educational and social goals of the project.

\section{CASE STUDIES}

\subsection{Introduction}

The two case studies presented in this paper departed from a cooperation established between two disciplines, archaeology and architecture, developed in partnership with two faculties the Faculty of Social and Human Sciences of the New University of Lisbon (NOVA FCSH) and the Faculty of Architecture, University of Lisbon (FA - UL), with several other partners

\footnotetext{
* Corresponding author
} 
associated depending on the project. This brought the opportunity to explore different methodological approaches in the study and documentation of built heritage, comparing and experimenting practices between archaeologists and architects, while having close the stakeholders and their needs.

Both projects were established as interdisciplinary field schools in heritage documentation, to give hands-on experience to students in the practice of recording built cultural heritage and its associated material culture. Students had experiences with traditional documentation methods, new technologies, and oral history, supported by the several professors involved, and had opportunities for discussions between peers and with other stakeholders, with mandatory public presentation of the work.

\subsection{Documentation work at the rice processing plant of Casa Cadaval, Muge, Portugal}

The research project of Casa Cadaval's Rice Processing Factory, in Muge, started with the identification by a researcher (Custódio, 2016) of the relevance of the site, who found in the owner eco in the intention to safeguard and enhance the unit.

Protected by its integration into Casa Cadaval's rural estate, and preserved by the affective attachment of the current owner, the Marquise of Cadaval, to the unit, this 1950's factory has remained to this day as a 'time capsule' in which both the original structure and the integrated machines were preserved in situ, as it gradually transformed into storage space to support the adjoining winery.

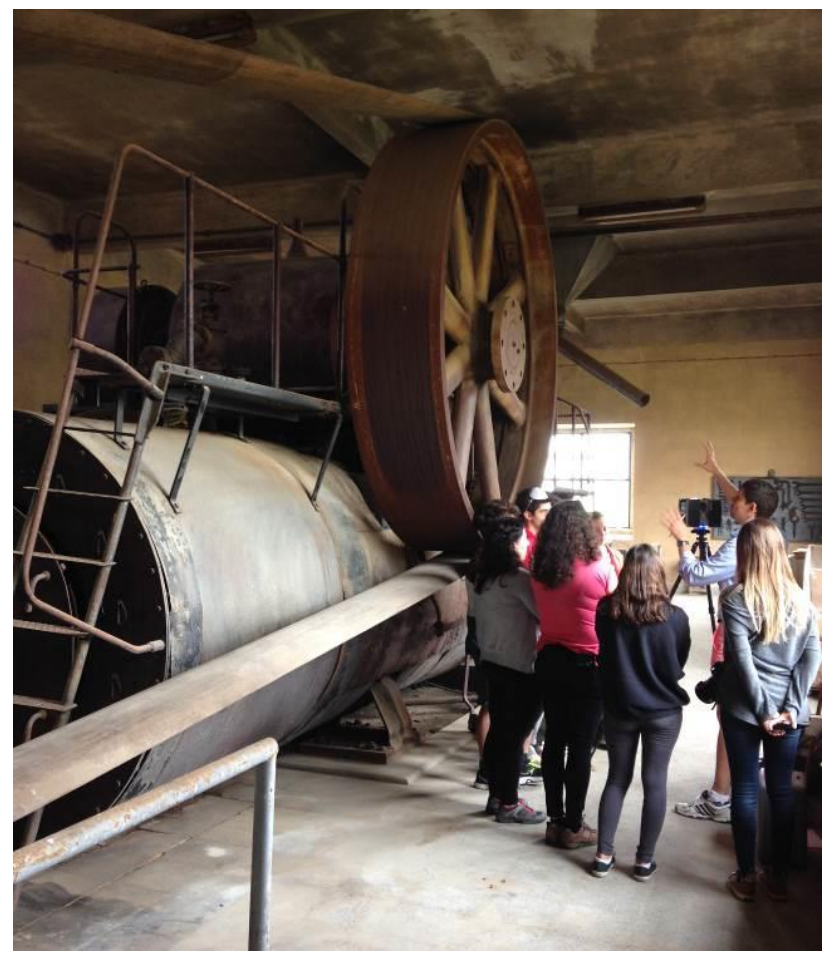

Figure 1. Beginning of the laser scanning of the steam engine room.

The main aspect of the factory was that it had preserved the machinery that corresponded to the cutting-edge technology of the time in the processing of rice, bought in Italy. It keeps its wooden grain elevators and sieves, stone grinders, and a steam engine brought from Germany after the war - which used the rice husks as fuel and which was also used to power the adjoining buildings, especially the main family house, the 'Palace'.
Contacted by the owner and the researcher, the national Portuguese Association for Industrial Archaeology (APAI) established a protocol with the universities NOVA FCSH e FAUL to develop the necessary fieldwork in documentation, as a first step to achieve knowledge and preservation (Medeiros 2019). Therefore, during the summer school break, students from the undergrad course in Archaeology and from graduate studies in Architecture took part in the diverse activities, monitored by their professors, authors of this article, having the opportunity to cross methodologies and experiment with techniques, such as inventory or laser scanning (Figures 1 and 2).

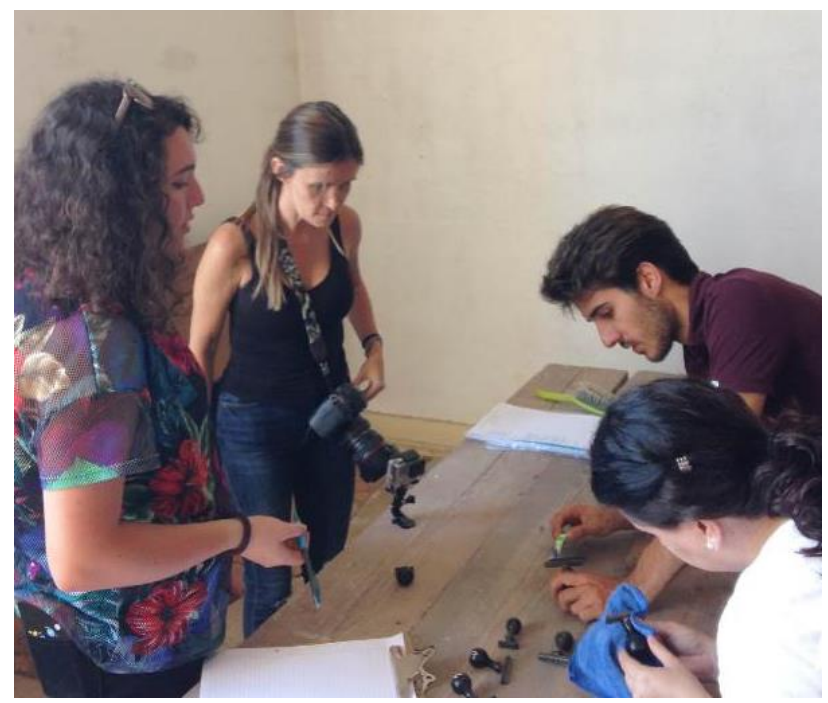

Figure 2. Students collaborating in the documentation of a set of company stamps, including cleaning, interpretation, inventory and photography.

During a week, students teamed up to rotate between the diverse activities: terrestrial and aerial photography, laser scanning, cleaning, organization and selection of the material, inventory, descriptive memory of areas, archival research, oral history, social media, and interaction with the visitors on open days.

In addition to the practice of methodologies many knew only from theory and classes, the interdisciplinary work allowed them to directly share methods between disciplines; students commented on how they were used to a certain way of drawing or taking measures and how here they were confronted with other ways, learnt from the coordinators and from the colleagues on the team.

By working in mixed groups of archaeologists and architects they were introduced to other ways of looking at the object and that made them recognise how those different disciplinary lenses brought up hidden details that enriched the story of the room, the object, the estate or the time period.

During the two open days, the students had also the opportunity to learn from former workers of the factory, their families and even the administration, as all freely walked around the place that had been closed for so long and which they now had the opportunity to re-visit and reconnect with. Students started by doing their usual research activities and explain them to the visitors, but when experiencing the engagement of the visitors, they ended up making questions and recording their oral histories. This knowledge also helped in filling in the inventory documents for objects and sectors, with data they wouldn't have been able to collect otherwise. 
After the summer work, other documentation fieldwork sessions took place with FA-UL's students of the course 'Practices in Digital Heritage', who then conducted the geodata processing task. Near 50 laser scanner stations and more than 2000 photos where processed under LIDAR and photogrammetric procedures. There was a dual goal on this development, first, to empower students with the capacity to accurately reconstruct as-built data and manage parametric and non-parametric models, and second, to create communication materials to further disseminate and promote the stories of the factory, from the more technical to the more historical.

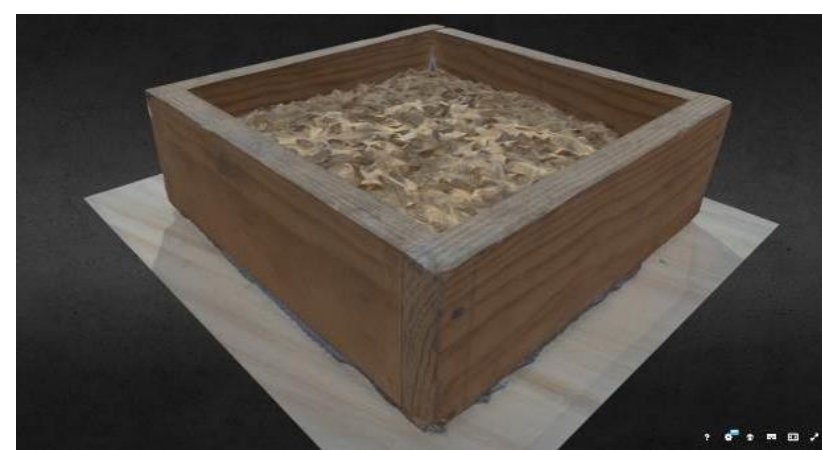

Figure 3. Textured 3D model of sieve filled with rice husks.

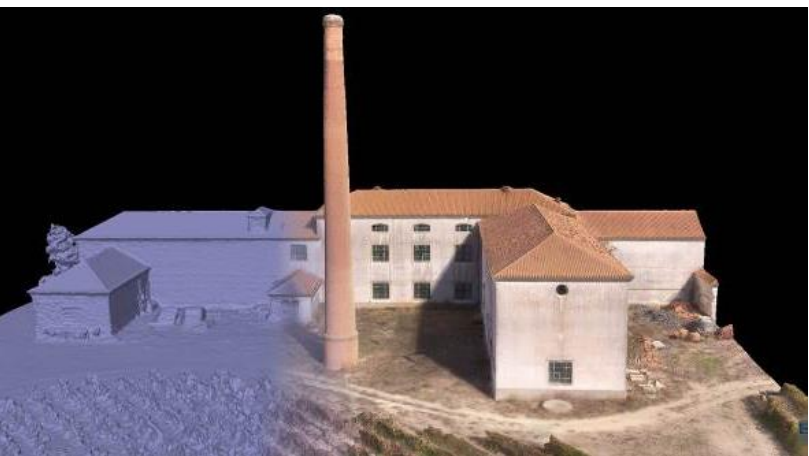

Figure 4. 3D model of the facility and the surrounding fields.

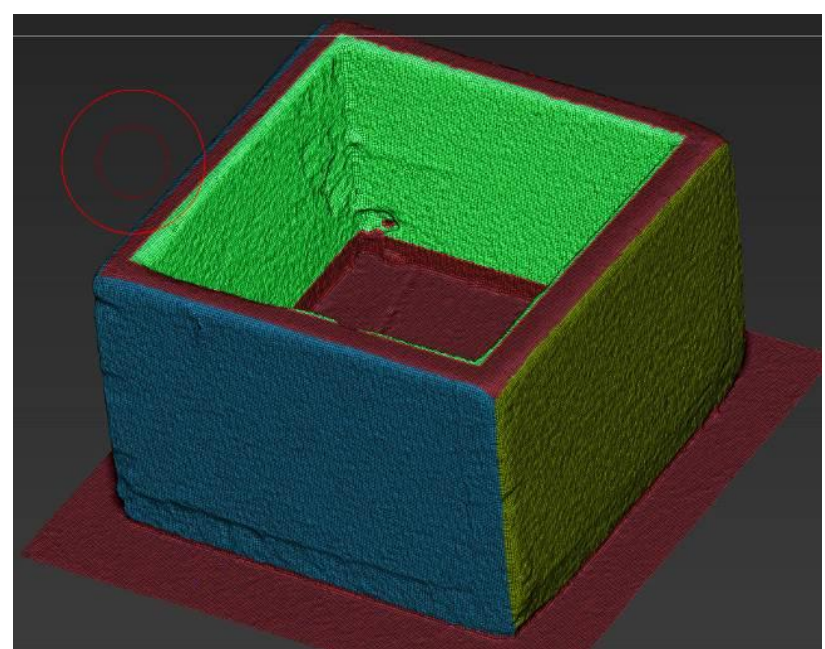

Figure 5. UV-organized mesh of rice measuring wooden cup

Given the complexity and diversity of the site, students where organized based on their interests, choosing to work in one of the various areas defined, from the micro-scale of the artefact (Figure. 3) to the macro-scale of the site and the landscape (Figure. 4), using different techniques to create the final digital items: parametric and non-parametric models.
The training also included Parametric and Organic modelling, including Scan-to-BIM modelling, grasshopper-based parametrization and retopologization of non-parametric models on data management, also to showcase the many outputs possible with the data collected by the students (Figures 6 and 7).

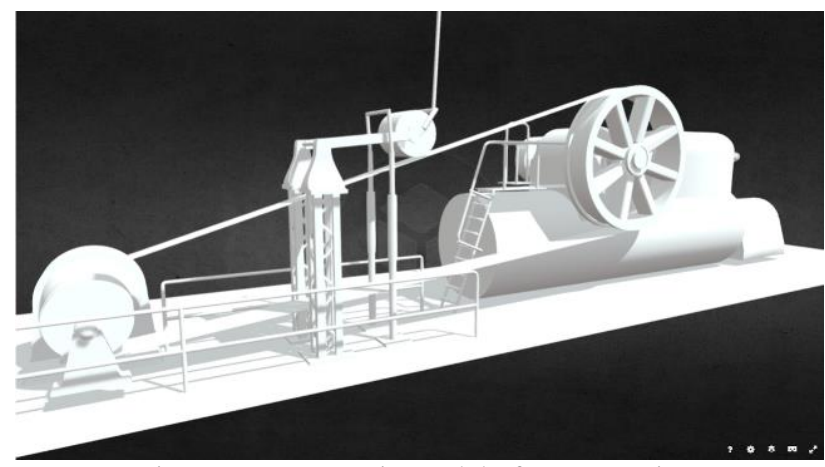

Figure 6. Parametric model of steam engine.

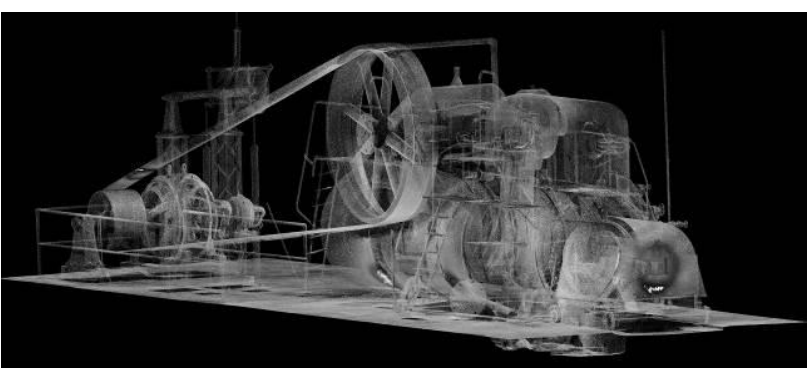

Figure7. Point-cloud figure of the steam engine.

\subsection{Hidden Hamina International Summer School, Finland}

The town of Hamina (Fredrikshamn), is located in the SouthEastern Finland, close to the Russian border. Built in the early 18th century, its ideal circular plan and star-like fortress system echoes Renaissance urban ideals, that make it still today a unique heritage site. It is also a place with a unique relation between the inhabitants and military culture, through the active Garrison, the military academy, and multiple events, a connection felt in the landscape and told by the material culture, its buildings and its people.

In 2016 the local community, through the Association of Old Houses and Courtyards of Hamina Fortress (Haminan linnoituksen wanhat talot ry), contacted the Tampere University of Technology (TUT), to explore together ways to support the preventive conservation of the city. This resulted in the completion of two successful projects: HALILAMA - Haminan linnoituksen rakennusten laserkeilaus ja 3D-mallinnus (2016) and the academic training course in Basics of Geospatial Processing (2017), with the $3 \mathrm{D}$ digital documentation of the outer surface of 23 main buildings and courtyards.

In 2018, the Association, together with the Hamina City and the University of Lisbon, joined forces to set up an informal experience to bring students from all over the world to continue the documentation of the city and learn from an experience of technical work in and with the community. The project had the support of Hamina City and the Google Research data centre in Hamina (Garcia-Fernandez, Medeiros, 2019b).

Both the Association and National Board of Antiquities of Finland highlighted the house cellars as being sensitive elements that required study from a historical perspective. Cellars are the 
oldest traces of the city's housing heritage in Hamina, namely because fires have played a role in the transformation of the historical area, especially inside the fortress limits. In the XIX century, the citadel was characterized by a compact and densely constructed wooden housing stock. The fire of 1821 destroyed $90 \%$ of the buildings including 110 houses, churches and government buildings; the fire of 1840 devastated 61 private houses including severely damages on the town hall, and finally the fire of 1887 destroyed 28 houses (Haminan, 2008).

Cellars were the only remaining structures after the fires, and they are now the oldest evidence of that built housing environment. Their survival also made them especially useful in the identification of the original property's location and as guidelines for the re-building process. As new legislation on mobility is expected to be implemented soon, cellars present an important challenge in accessibility and pedestrian mobility, with the proportion of footprint and riser, irregularities on grading, and several mobility barriers in access points, which will likely require changes and cause loss of authenticity.

To address both the need to preserve the cellar and to analyze its geometry for further accessibility projects, two cellars from two historical houses were selected to be studied. Three main content groups were organized along one intensive week: (i) Freehand measuring drawings; (ii) Laser Scanning and Photogrammetry for Built-environment documentation; and (iii) Archaeology of Architecture, an applied used of remote sensing-based documents. The course especially integrated with a socio-cultural agenda to transmit a living experience of the city, and a deeper immersion in Hamina's cultural values.
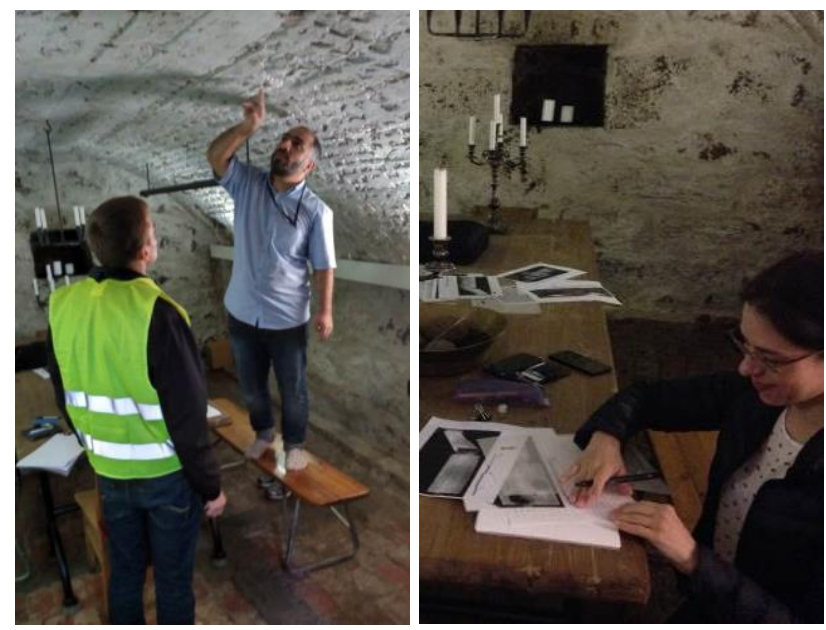

Figure 8. Students analysing the anomalies of cellar's vault and proposing interpretations of the space based on the evidence.

Through an intense program, which combined several experts and case studies, students had theoretical and practical experience, with fieldwork sessions, hands-on training on data management, and also an active social calendar with the community.

The teams of students tried different surveying and measurement techniques, processed the corresponding data, and used it to interpret and present the conclusions regarding both technical and historical aspects of the cellars (Figure 8). The 2D and 3D documents produced along the week were carefully treated to answer the initial request of our partners. A large set of metric maps (Figure 9), spatial analysis (Figure 10) and historic interpretation were developed and delivered.
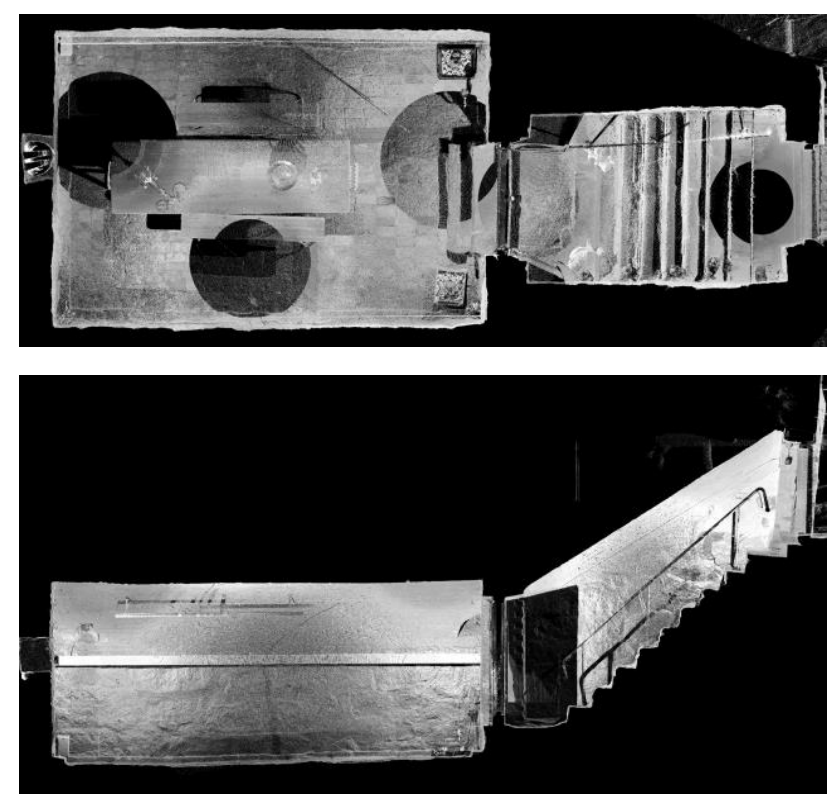

Figure 9. Detailed top-view orthoimage (top) and cross-section obtained from laser scanning data.

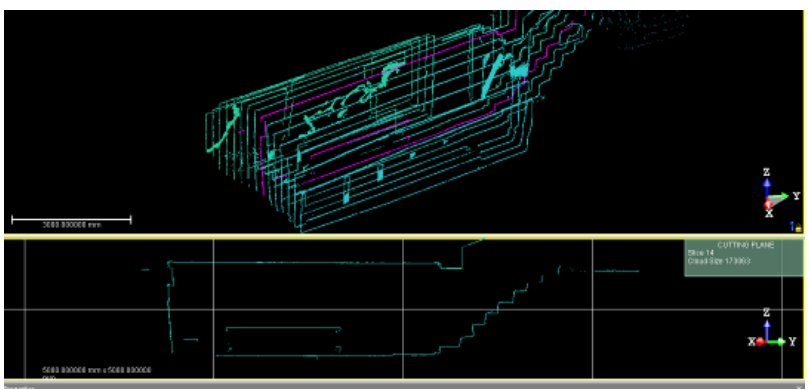

Figure 10. Cross section in Y axis in selected cellar.

During the fieldwork sessions, students had to train surveying methods on harsh environments of poor lighting conditions and complex access. They then compared and discussed the pros and cons of both classic and new strategies of building documentation, an essential part in our educational approach.

In addition to the training, the course took advantage of the multidisciplinary (architects, archaeologist, artist, $\mathrm{CH}$ managers, surveyors) and multicultural (8 different countries) cohort of students, sharing and complementing the different visions on heritage preservation. A final session was hosted at the City Hall, where students were able to present directly the results of their work but also decided to transmit their own personal story with the site and the people who had received and hosted them.

\section{DISCUSSION}

\subsection{Giving a voice to inanimate objects}

"If these walls could talk" is an old saying that points out how buildings and objects share our lives, silently, without us giving them much consideration, present when we share confidences, moments and stories. As generations pass, the changes to these walls are constant and frequent, and their survival is often challenged by human and natural reasons. The dialectic relationship humans establish with these sites, which we can see as the transformation of space into place (Cresswell, 2004), leaves marks imprinted in the walls. Sometimes they are 
evidences of absence, when something is removed from the site, others are shadows created by constant use, as the rubbing of a chair against a wall. These are the types of evidence that are to be identified and transformed from fact into story if they are to become knowledge that provokes emotion and connection, and, as put by Tilden regarding site interpretation, take others on the causal process of understanding, appreciating and protecting (Tilden, 1957).

When doing documentation field work the role of the archaeologist is to interpret the evidences left by marks on those walls and other surfaces, by the distribution and state of the objects, and to create a narrative of the human interaction with the site from the materials, and this is not always an easy or objective task. Pierce Lewis' words on landscapes are applicable to buildings as well, as they are "our unwitting autobiography, reflecting our tastes, our values, our aspirations, and even our fears, in tangible, visible form", an autobiography, the author argues, that "is liable to be more truthful than most autobiographies" because we are indeed not expecting it to be read as a book, therefore being less 'self-conscious' about how we shape and mark the building (Lewis 1976, p. 6). Reading such an object therefore needs, and is subject to, interpretation. Even if we can argue that many buildings were designed with specific symbols (shapes, materials, decorations, etc.) meant to convey a message of power, wealth, or strength, among many, we are less conscious about the evidences of use we imprint on them, especially when these are performed by need or habit. But these are the soft evidences that, by constantly leaving a mark on the walls or objects, can be used to make them talk about the lives of those who made them, and usually about the anonymous workers and dwellers of these sites. And the lack of a voice is stronger in vernacular places and functional objects, who lack the connection to an owner, artist, architect or brand, those which are functional.

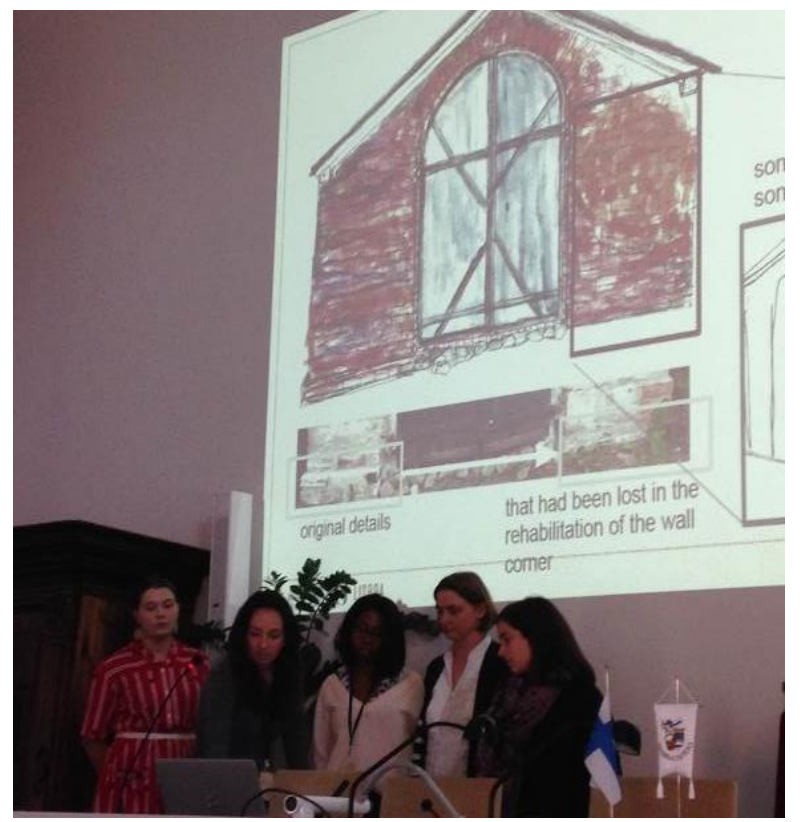

Figure 11. Presentation of the work developed, including the stories discovered through interpretation of evidence of historic use and recent adaptations.

In the case studies presented the interest came not from an outside view of the object, but from the owners insistence on the need to value their heritage, which found resonance in the academic environment and put into action both research and community activities that ended up bringing up stories and forging connections that now put those sites in a better position for preservation, dissemination and valorization (Figure 11). We can say that there was a voice from these sites that was already known by the local community, but which had been silenced at some point in time (usually by a change in use or ownership) and which was being missed. The expertise from professionals and researchers in many fields, and the energy and curiosity from the students, helped the community bring out the stories and promote their heritage.

\subsection{Rethinking expertise in the work with communities}

As heritage professionals increasingly became aware of the need to re-evaluate their role(s) - with the development of critical heritage studies and the definition of authorized heritage discourse iconically pointed out in Laurajane Smith (2006) there has been the need to coin new practices and approaches to heritage work, especially when it involves strong and present heritage communities. This is clearly a big topic not suited to treat in the scope of this article, but which we felt was stirred by the projects mentioned.

The case studies did not correspond to the traditional research work, since they had from the start a construction as education opportunities occurring during research projects, but they still aimed at integrating the principles of Community Based Participatory Research (Atalay, 2012) that defend research done with and by the communities, from who the research question departs as well.

In the cases presented, there was indeed a proposal of research that came from the local community of the sites, with the primary goal being to answer their specific request, but which was then refined and adapted to adjust to academic procedures, and even school schedules. There was an awareness of the potential of contributions from multiple knowledge systems under the principle of "braided knowledge", where "community knowledge intertwines with archaeological data to create new and richly textured interpretations of the past" (Atalay, 2012), and these were attempted by working closely with the workers of the estate and with former workers of the factory during the open days. We also believe that the stories students heard from community members will percolate and lead to long-term effects in the practices of all involved (Figure 12), not just in the results of the work.

A surprising knowledge that was braided with the technical work came from the students themselves, with their appetence for social media, photography skills, and the informal exchange of experiences and knowledge among themselves, a result we weren't foreseeing when we first started. If many stakeholders often feel 'unconfident or unqualified' to participate in the discussion on heritage identification and management (Schofield, 2016) it became clear that the creation of diverse communication platforms, some more formal, others non-presential, some spontaneous, helped different participants express their views in the way they felt more comfortable and still have that perspective included in the work done.

When it comes to cultural heritage and knowledge, as promoted by the Faro Convention, on the Value of Cultural Heritage for Society (CoE, 2005), fieldwork such as this helps achieve the goals of including the cultural heritage dimension at all levels of education, promoting vocational training, interdisciplinary work, the "continuous professional training and the exchange of knowledge and skills, both within and outside the educational system" (CoE, 2005, p. 13). 


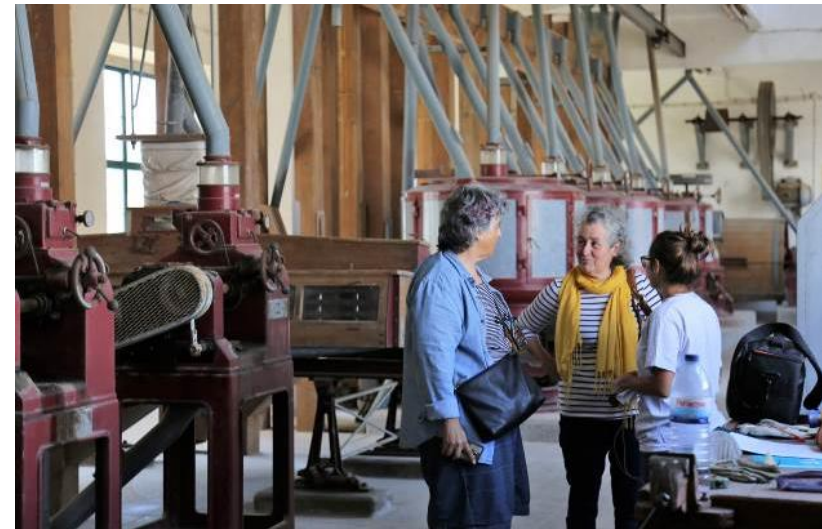

Figure 12. Informal moment of exchange between a student (on the right) and community members, during an open-day at the old rice transformation facility.

The projects also promoted active participation in the process of identification, study, interpretation, protection, conservation and presentation of the cultural heritage, public reflection and debate, recognised the role of voluntary organisations both as partners in activities and as constructive critics of cultural heritage policies, and took steps to improve access to the heritage, especially among young people (CoE, 2005, p. 12).

\subsection{New Technologies}

In these projects new technologies took centre stage in two main fields: documentation and dissemination. The inventory and recording purposes of the work were seen as key points to help know and preserve the heritage sites, and this is an area that has always transformed with the surge of new technologies. In terms of documentation of built heritage, the evolution of remote sensing technologies, such as laser scanner and photogrammetry or new processing algorithms based on computer vision, have greatly improved the quality of the data collected, with increased precision and the multiplication of possible outputs of the information collected.

For the actualization and the preparation of the new professionals in this field, inserting new technologies in the study program is key. But it is also often hindered by the limitations in the available knowledge and access to the (often expensive) materials. In these projects the technological dimension and the crossing of methodologies was a clear attraction factor, and provided to many of the students their first contact with these practices. Fieldwork such as the ones developed for these sites, granted students access to the use of these technologies and also to their contextualization in terms of research questions, scientific research and needs of the users.

We are of the opinion that a contextualization of the history of usage of these new technologies in documentation is important for the students, especially for them to fully understand both the opportunities brought by their usage, and the limitations, teaching them to respect the still essential role of the human operator of the technology. As such, we kept the traditional ways of measuring and documenting the sites, using their own measures (like their feet or hands) or measuring tapes, through graphic hand drawing of the sites, and written documentation. These practices were also included to force the students to look in detail to the walls, floors, objects and other evidences that only become clear with the direct and prolonged contact with the site.
Then, by introducing photogrammetry and laser scanning, and by using the resulting products (like elevations, plants and sections of the site) in the interpretation of the site, we could discuss the benefits of new technologies in documentation, namely in terms of time spent documenting and precision of the results. We also made the case for how the time-consuming task of documenting a site by hand brought up questions and details of use that would have been missed if we had only used digital tools. With the complementarity of both classic survey methods and new remote sensing and digital techniques, we achieved a greater efficiency in the registration of both geometries and attributes of our sites.

Although surveyed Geodata (with a high level of accuracy and resolution) is not always straightaway compatible with dissemination channels, these courses dedicated special sessions to transform data to be read by wider publics: adapted to end-user devices, readable in large-audience channels, and with the capacity to be represented in $2 \mathrm{D}$ formats.

In order to overcome the limitation of spatial comprehension on complex three-dimensional environments, efforts were also put on linking physical and digital realities together. Through the development of Augmented Reality experiences, students created accurate scale-reduced models and placed them in their original locations, as preserved-dimensional 3D models. These were them presented publicly at APAI during an informal conference and the documents were offered to the audience and stakeholders (Figure. 13).
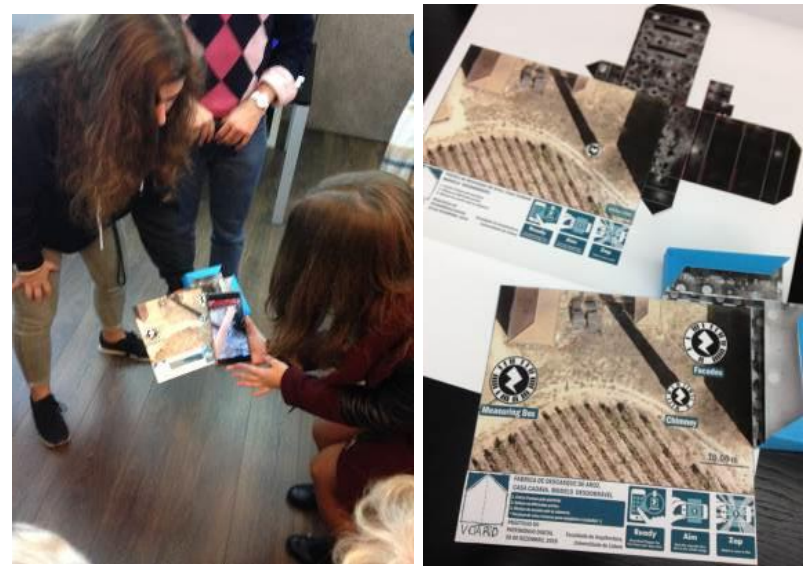

Figure 13. Buildable scaled-model with AR code connection, bringing together physical and digital representations.

Another way in which new technologies were applied was in the dissemination and communication of the projects. One of these involved social media, with both projects being active in platforms such as Facebook and Instagram, which were in great part fed by the students; as part of their work in the project they were to document their activities and their interactions and share them to a common platform.

As such, the sharing of moments of the research took place as it was developing, and it made it informative, academic, but also light and young, as students decided to share photos of the food or themselves. In the case of the work in Muge (\#ArqIndFDACC), it was decided to inaugurate a social media page for the association APAI and use it for this project, but also use the hashtag to post in personal pages of the team members (Figure. 14). 


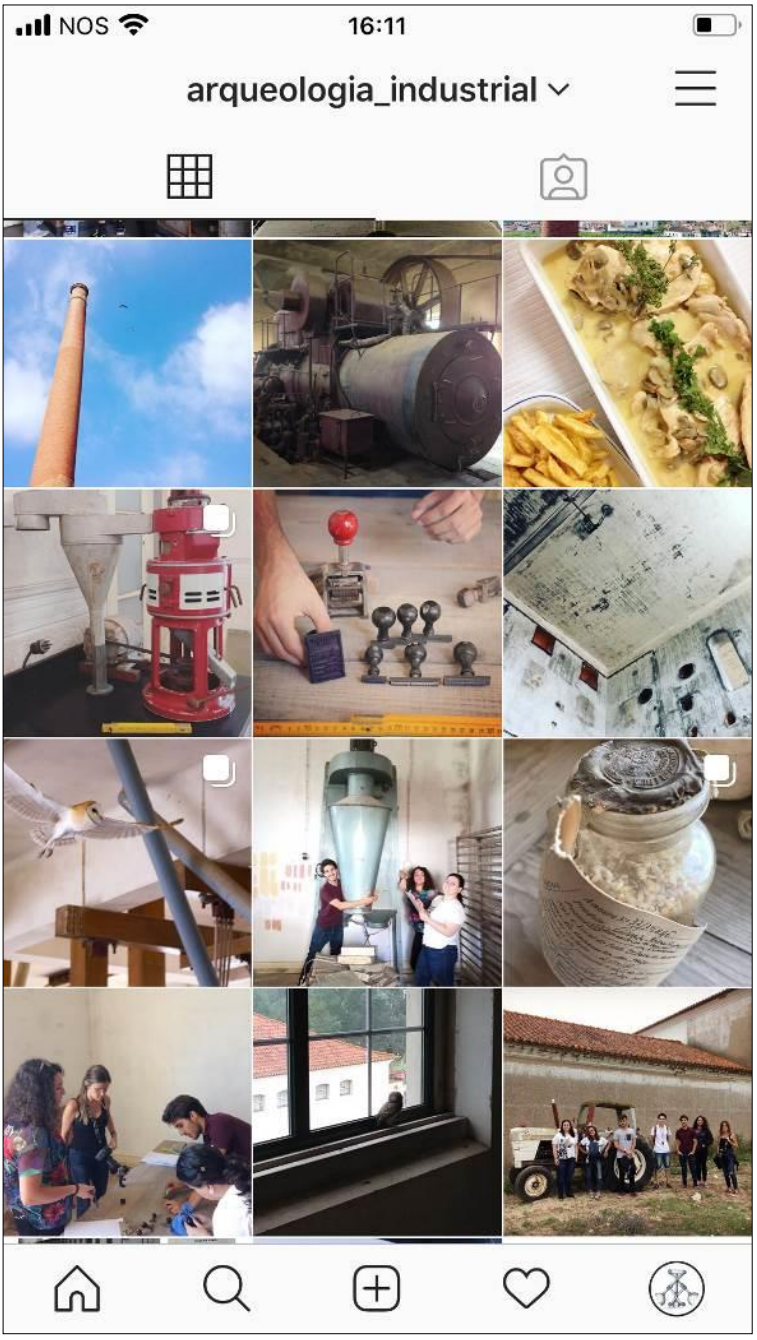

Figure 14. Some of the student-curated pictures during fieldwork in Muge.

\section{FINAL CONSIDERATIONS}

The research done at the sites presented in this paper shared an ideal of finding and documenting history and stories through direct contact with the built heritage and its communities. Making the sites and their associated objects 'talk' has been for long a key aspect of archaeological work, one that requires constant review as new technologies bring new tools with which to work. An interdisciplinary approach between archaeology and architecture facilitated the integration and adaptation of these new tools in field work, data processing, and communication, while also allowing to use them critically and consciously.

It is no surprise that tools such as digital photogrammetry and laser scanning, which expand the human limitations of the eye and the hand, have allowed us to 'read' more into buildings and objects than we could previously, and to do it faster. Slight deformations and almost imperceptible marks can be enhanced and discovered with the aid of these new technologies. Limits on accuracy and resolutions are getting smaller, and new affordable sensors (such as thermographic, radar, etc.) are being included in the built-environment survey. But what the fieldwork as also shown is how important it is to continue to spend time physically interacting with the places through our human senses and our curiosity. And it was surprising to see how the connection between observer and observed was being created by the act of looking, registering and interpreting, with long lasting effects on the relation of the students with the sites and their owners.

The complexity of the entanglements between humans and things - defined by archaeologist Ian Hodder as a dialectic interaction "compounded by conceptual abstractions and bodily resonance, a reverberation between mind, body and the world of things" (Hodder, 2012, p. 206) that in our brains generate new entanglements with what we take with us previously - leads to a richness of stories that are impossible to retrieve in their entirety form the sites. But the process of research can become the process of creation of new reactions, of new entanglements that add to the richness of the meanings and values of that heritage, confirming that places are "the perceptual as well as physical product of people and communities" (Fairclough, 2009, p. 153).

It is also the process of creation of new heritage communities, as was created by the group of students and professors that bonded with the site and with their stakeholders through intense fieldwork, site visits and conversations. The emotion of site discovery, of time spent inside and outside, of group effort, of community engagement, all reinforced the heritage value of the buildings and therefore created new promotors of their protection and valorisation. These connections, they have now passed on to others in their networks, and, with a relevant help from new technologies and social media, also with anonymous digital communities that remotely now can also know about these sites.

For the local communities involved, the simple act of people outside of their towns, even outside of their country, coming over to document their sites, was an act of recognition and validation that inflates new energy to preservation efforts. In the case of Muge, it was evident that the opportunity for ex-workers to re-enter the plant and reconnect to a key place in their personal and family history was the highlight of the experience, more than any technical explanation or historical curiosity that the 'experts' could present.

The fact that today we can register those stories and spread them more widely is an incredible opportunity for heritage preservation. As mediators between the students, the communities and the sites, we reviewed our role as 'experts' to a more fluid exchange of knowledge, be it by letting students manage social media or by just listening in to visitors talk on the open-days - those originally planned to share information in a 'hierarchical' way but which instead became a fruitful exchange. As such, indeed 'we are all heritage experts' (Schofield, 2016).

Material cultural heritage is potentially an immense source of inspiration and connection, be it from a small stamp or sieve, a big steam engine or a house, and even coming from of our recent past. The diversity of 'eyes' - be it the specialist eye, the local eye, the digital eye, etc. - that we take on board the projects to look at the sites, their surroundings, and the associated needs, are fundamental to extract stories from their past and are also key in creating new stories, which come out to be as relevant (or more) in the journey for their future preservation. Also, the products that can result from the use of new technologies have the possibility to adapt to specific audiences and specific knowledge needs, and also to expand the impact of the data collected through its adoption of different visual formats and dissemination through several online platforms.

\section{ACKNOWLEDGEMENTS}

The authors acknowledge the invaluable support of the partners and students involved in the projects presented. 


\section{REFERENCES}

Atalay, S., 2012. Community-Based Archaeology: Research with, by, and for Indigenous and Local Communities. University of California Press.

CoE, 2005. Convention on the Value of Cultural Heritage for Society. Council of Europe.

Cresswell, T., 2004. Place: A Short Introduction. WileyBlackwell.

Custódio, J., 2016. A Fábrica de Descasque de Arroz da Casa Cadaval: Património Industrial de Muge. Magos, Revista Cultural do Concelho de Salvaterra de Magos, 3, 167-216.

Fairclough, G., 2009. "Place-making and place-shaping". Heritage and beyond, Council of Europe, 153-154.

Garcia-Fernandez, J., Medeiros, L., 2019a. Cultural Heritage and Communication through Simulation Videogames - A Validation of Minecraft. Heritage, 2, 2262-2274. doi.org/10.3390/heritage2030138.

Garcia-Fernandez, J., Medeiros, L., 2019b. Integrating Digital Documentation and Community Engagement: 'Unveiling The Hidden Hamina' International Summer School. ISPRS Ann. Photogramm. Remote Sens. Spatial Inf. Sci., IV-2/W6, 61-68. doi.org/10.5194/isprs-annals-IV-2-W6-61-2019.

Haminan kulttuuriympäristöohjelma, 2008. Valleilta Kartanoihin - Saaristosta Kaskimaille. Hamina City Ed. available at https://www.hamina.fi/wpcontent/uploads/2018/02/Kulttuuriymparistoohjelma_2008_ylei nen_09122010.pdf

Hodder, I., 2012. Entangled - An Archaeology of the Relationships between Humans and Things. Wiley-Blackwell.

Lewis, F. P., 1976. Axioms of the Landscape: Some Guides to the American Scene. Journal of Architectural Education, 30:1, 6-9, DOI: $10.1080 / 10464883.1976 .10758067$

Medeiros, L., 2019. Trabalhos Arqueológicos na Fábrica de Descasque de Arroz da Casa Cadaval (Salvaterra de Magos): Tecnologia, Património e Comunidade. Al-Madan online, 22(tomo 3) Jan, 9-19.

Schofield, J., 2016 "Heritage expertise and the everyday: citizens and authority in the twenty-first century." Who Needs Experts? Routledge, 17-28.

Smith, L., 2006. Uses of heritage. Routledge.

Tilden, F., 1957. Interpreting our Heritage. University of North Carolina Press. 